\title{
Anti-Myeloperoxidase Antibodies in Crescentic
} Glomerulonephritis ${ }^{1}$

\begin{tabular}{|l|l|}
\hline X. & \\
\hline E. & Bosch $^{\mathrm{a}}$ \\
\hline J. & Mirapeix $^{\mathrm{b}}$ \\
\hline M. & Font $^{\mathrm{a}}$ \\
\hline L. & Ingelmo $^{\mathrm{a}}$ \\
\hline
\end{tabular}

Departments of ${ }^{\mathrm{a}}$ Internal Medicine and ${ }^{\mathrm{b}}$ Nephrology, Hospital Clínico y Provincial, Barcelona, Spain

Dr. Xavier Bosch, Servicio de Medicina Interna General, Unidad 1, Hospital Clínico y Provincial, Villarroel, 170, E-08036 Barcelona (Spain)

Dear Sir,

Nässberger et al. [1] have recently reported the occurrence of anti-neutrophil cytoplasmic autoantibodies (ANCA) in sera from patients with crescentic glomerulonephritis (CGN). Among 64 patients with this disease, ANCA were detected in 47 (73\%). By indirect immuno-fluorescence, a cytoplasmic pattern (C-ANCA) was seen in $44 \%$ of the patients, mainly in those having a diagnosis of Wegener's granulomatosis (WG). In contrast, a perinuclear pattern (P-ANCA) was seen in 30\%, mainly in those with CGN without evidence of extrarenal involvement.

Furthermore, as judged by enzyme-linked immunosorbent assay (ELISA), all P-ANCA sera corresponded to anti-myeloperoxidase (MPO) antibodies.

We wish to report our experience of ANCA in CGN. Our study included a series of 24 consecutive patients with a pathological diagnosis of CGN. ANCA were tested by an indirect immunofluorescence assay on etha-nol-fixed neutrophils, as previously described [2]. In addition, we realised a previously unpublished method in order to know in which cases ANCA were directed against MPO. Thus, indirect immunofluorescence was also performed on neutrophils which were previously known to have an absence of this enzyme. This rare condition may be easily detected in an ordinary blood analysis using a Technicon H-l autoanalyzer (Technicon, Tarrytown, N.Y., USA). Sera giving a positive result with normal neutrophils and a negative one with neutrophils devoid of MPO were considered to possess anti-MPO antibodies. These results were later confirmed by ELISA using purified human MPO.

1 Supported in part by grants from the Hospital Clínico y Provincial de Barcelona (1990) and the Direcció General d’Universitats de la Generalitat de Catalunya (Formació d'investigadors 1990). Table 1. Distribution of ANCA in 24 consecutive patients with CGN Patients ANCA C- P- MPO-

n ANCA ANCA ANCA

$\begin{array}{llllll}\text { Idiopathic CGN } 19 & 12 & 2 & 10 & 10 ! \\ \text { PAN-associated CGN 4 } & 4 & 0 & 4 & 4 \\ \text { WG-associated CGN 1 } & 110 & 0 & & \end{array}$

Six males and 4 females. 
Fig. 1. Immunostaining of neutrophils on immunofluorescence microscopy. Note the diffuse staining of nuclei with dense endonu-clear bands typical of anti-MPO antibodies. $\times 100$. The distribution of ANCA in the study patients are summarised in table 1. Among 24 patients with CGN (15 males and 9 females), 19 were categorised as having an idiopathic CGN without extrarenal involvement (group 1), whereas in 5 patients the disease was judged as being secondary to a vasculitic disorder, classical polyarAnti-Myeloperoxidase Antibodies in Crescentic Glomerulonephritis 505

teritis nodosa (PAN) being diagnosed in 4 patients and WG in 1 (group 2). ANCAwere detected in 17 cases (71\%), 14 of them corresponding to P-ANCA and 3 to C-ANCA. When carefully examined, all patterns named P-ANCA were observed as a diffuse nuclear immunostaining of neutrophils with additional endonuclear bands (fig. 1). This type of pattern was seen in 10 patients of group 1 and in 4 of group 2 (those with PAN). In all P-ANCA-positive cases, a negative immunofluorescence was evident at the minimal dilution (1:20) when neutrophils deficient of MPO were used. We then concluded that these patients presented ANCA with specificity for MPO, and it was later confirmed by ELISA in all the cases. Finally, only 2 patients of group 1 and 1 of group 2 (biopsy-proven WG) had a clear cytoplasmic pattern which was undistinguish-able from the control one of a patient with WG.

At present, it has been accepted that ANCA have several antigenic specificities which in turn identify several clinical disorders. Thus, C-ANCA mainly correspond to anti-proteinase 3 antibodies which are strongly associated with most cases of histologically-proven WG. In contrast, most P-ANCA correspond to anti-MPO antibodies which identify most cases of idiopathic necrotis-ing and CGN [3-8]. However, there is a substantial overlap in disease distribution among patients with both antibodies.

According to our and other results $[1,3-6,8,9]$, it is our opinion that in cases of CGN without evidence of systemic involvement, the presence of P-ANCA, especially anti-MPO antibodies, identifies a systemic vasculitis other than WG, probably PAN limited to the kidney. On the contrary, the presence of C-ANCA, especially anti-proteinase 3 antibodies, identifies cases of WG also limited to the kidney. Indeed, the higher incidence of P-ANCA than C-ANCA in idiopathic CGN probably reflects the differences in the general incidence between PAN and WG. Finally, Andrassy et al. [9] have recently reported a predominant affection of females in their group of patients with anti-MPO antibodies-associated idiopathic CGN (21 females and 2 males), thus suggesting that it could be an entity linked to female sex. However, we have not found differences in the sex incidence in these cases (table 1).

References

Nässberger L, Sjöholm AG, Thysell H: Antimyeloperoxidase antibodies in patients with extracapillary glomerulonephritis. Nephron 1990;56:152-156.

Cohen Tervaert JW, van der Woude FJ, Fauci AS, Ambrus JL, Velosa J, Keane WF, Meijer S, van der Giessen M, The TH, van der Hem GK, Kallenberg CGM: Association between active Wegener's granulomatosis and anticytoplasmic antibodies. Arch Intern Med 1989;149:24612465.

Falk RJ, Jennette JC: Anti-neutrophil cytoplasmic autoantibod-ies with specificity for myeloperoxidase in patients with systemic vasculitis and idiopathic necrotizing and crescentic glomerulonephritis. N Engl J Med 1988;318:1651-1657. 
Jennette JC, Wilkman AS, Falk RJ: Anti-neutrophil cytoplasmic autoantibody-associated glomerulonephritis and vasculitis. Am JPathol 1989;135:921-930.

Goldschmeding R, van der Schoot CE, ten Bokkel Huinink D, Hack CE, van den Ende ME, Kallenberg CGM, von dem Borne AEGK: Wegener's granulomatosis autoantibodies identify a novel diisopropylfluorophosphate-binding protein in the lyso-somes of normal human neutrophils. J Clin Invest 1989; 84:1577-1587.

Cohen Tervaert JW, Goldschmeding R, Elema JD, van der Giessen M, Huitema MG, van der Hem GK, The TH, von dem Borne AEGK, Kallenberg CGM: Autoantibodies against mye-loid lysosomal enzymes in crescentic glomerulonephritis. Kidney Int 1990;37:799-806.

Ludemann J, Utecht B, Gross WL: Anti-neutrophil cytoplasmic antibodies in Wegener's granulomatosis recognize an elastino-lytic enzyme. J Exp Med 1990;171:357-362. Jennette JC, Falk RJ: Antineutrophil cytoplasmic autoantibodies and associated diseases: A review. Am J Kidney Dis 1990;15:517-529.

Andrassy K, Koderisch J, Schäfer A, Waldherr R: Idiopathic rapidly progressive (crescentic) glomerulonephritis with myeloperoxidase antibodies - A new entity linked to female sex? Nephron 1990;56:99-100. 